\title{
PRELIMINARY STUDY OF INSULIN DRY POWDER FORMULATION: CRITICAL PROCESS PARAMETERS ON SPRAY-FREEZE-DRYING AND CRITICAL MATERIAL ATTRIBUTES OF TREHALOSE AND INULIN AS STABILIZER
}

\author{
CYNTHIA MARISCA MUNTU ${ }^{1}$, SILVIA SURINI ${ }^{*}$, CHRISTINA AVANTI ${ }^{3}$, HAYUN $^{2}$
}

1Department of Pharmaceutics and Pharmaceutical Technology Development, Faculty of Pharmacy, Universitas Indonesia, Depok 16424, West Java, Indonesia, ${ }^{2}$ Laboratory of Pharmaceutical and Medicinal Chemistry, Faculty of Pharmacy, Universitas Indonesia, Depok 16424, West Java, Indonesia, ${ }^{3}$ Department of Pharmaceutics, Faculty of Pharmacy, Universitas Surabaya, Surabaya 60293, East Java, Indonesia *Email: silvia@farmasi.ui.ac.id

Received: 20 Aug 2021, Revised and Accepted: 01 Oct 2021

\section{ABSTRACT}

Objective: The aim of this study was to obtain recommendations about critical process parameters (CPP) and the optimal ratio of trehalose and inulin as critical material attributes (CMA) on insulin dry powder formulation with spray-freeze-drying (SFD) method.

Methods: Inulin dry powder was formulated with the SFD method, which consisted of an atomization process and freeze-drying (FD). SFD processes were optimized in order to obtain dry powder and CPP was analyzed. All seven variations of formulas proceeded with physicochemical characterization to obtain the optimal formula.

Results: In the early optimization, there was a slight time lag between the atomization process and FD; as a result, some of the powder coagulated and crystallized. Another critical parameter was that the FD process should not be interrupted for at least $50 \mathrm{~h}$ of FD. Dry powder proceeded with physicochemical characterization, a formula without inulin showed semicrystalline properties, while six formulas had amorphous properties due to its combination. All formulas had a spherulite shape and rough surface. Five formulas with the combination of trehalose and inulin obtained dry powders with a diameter range of 30-43 $\mu \mathrm{m}$, moisture content below 3.5\%, and high encapsulation efficiency (EE). Formula with the ratio of 1:1 (F4) showed optimal properties with moisture content and EE of $2.62 \%$ and $99.68 \%$, respectively.

Conclusion: This study concluded that there were two critical process parameters in the SFD method. There should be no delay in the SFD process and when the FD is in operation, it should not be interrupted until the powder is dry. The optimal ratio for trehalose and inulin was shown by F4 with ratio of $1: 1$.

Keywords: Insulin, Dry powder, Trehalose, Inulin, Preliminary study, Critical process parameters, Critical material attribute, Formulation, SFD

(C) 2021 The Authors. Published by Innovare Academic Sciences Pvt Ltd. This is an open access article under the CC BYlicense (https://creativecommons.org/licenses/by/4.0/) DOI: https://dx.doi.org/10.22159/ijap.2021.v13s4.43823 Journal homepage: https://innovareacademics.in/journals/index.php/ijap

\section{INTRODUCTION}

Typically, insulin is formulated as a solution in water which has a limited shelf life and often requires keeping refrigerated $\left(2-8{ }^{\circ} \mathrm{C}\right)$ during storage and transportation [1]. To increase stability, insulin can be formulated in dry form. In addition, storing insulin in dry form may drastically reduce the degradation rates due to limited molecular mobility [2]. However, during the drying process and storage, insulin can be exposed to stress, including freezing and drying with high pressure and low temperature, which causes damage to its integrity. Therefore, protection against exposure to stress during manufacturing and storage is needed. One strategy in the aspect of insulin stabilization is to form dry proteins with additional stabilizers such as sugar [3-5]. Adding sugar into an existing protein usually means immobilizing protein molecules in sugar glass matrices.

Sugar that has been widely used as a protein protector in solid protein formulations are glucose, sucrose, trehalose, inulin, dextran, and pullulan. Not all proteins can be stabilized through coating with simple sugar. Coatings with small sugar result in a tight coating and poor physical stability, particularly in high relative humidity (RH) due to its relatively low glass transition temperature (Tg). In contrast, coating with rigid oligo-or polysaccharide produces non-tight coating and excellent physical stability.

In the disaccharide/oligosaccharide group, trehalose has a higher $\mathrm{Tg}$ value than sucrose, so its capacity for stabilization is also better [6]. Trehalose is reported to have the highest stabilizing capacity compared to inulin and dextran, which are polysaccharides as well as a combination of dextran and trehalose $[7,8]$.

The polysaccharide groups that were often used in protein stabilization are inulin, dextran and pullulan [6, 9-13]. Inulin was reported to have a better stabilizing capacity for bovine serum albumin than glucose and sucrose [10]. Inulin has a more flexible structure than dextran related to the linearity of its structural chain so that it can provide a better coating capacity [14].

Several disadvantages of using a single sugar encourage the use of a combination of disaccharides and polysaccharides [14]. In this study, the combination of trehalose and inulin was chosen because trehalose is a non-reducing sugar and has a high Tg value [11]. The combination with inulin was chosen because of its high Tg value and flexibility in protein coating $[10,14]$.

Dry powder was formulated using the Spray-Freeze Drying (SFD) method due to the temperature-sensitive character of insulin [15] and the spherical particle, which meets the intranasal dry powder specification [16]. The preliminary study was needed in order to analyze CPP on SFD, which was affected by the dry powder characteristic. Physicochemical characterization was carried out to analyze CMA on trehalose and inulin formula ratio criteria, including identification of Tg and thermal energy, crystallinity properties, moisture content, particle morphology, particle size distribution and efficiency encapsulation.

\section{MATERIALS AND METHODS}

Formula composition

The dry powder formula consisted of human recombinant insulin (Sigma), HCl (pro analysis), trehalose (pharmaceutical grade), inulin (pharmaceutical grade), HPMC E5 (pharmaceutical grade) and Poloxamer 188 (pharmaceutical grade). The weight ratio of insulin and sugar used was 1: 1000, with seven variations of trehalose and inulin weight ratio $[11,13]$. The seven formula ratios (table 1) were 1:0 (F1), 5:1 (F2), 2:1 (F3), 1:1 (F4), 1:2 (F5), 1:5 (F6), 0:1 (F7). The weight ratio of insulin and sugar used was 1: 1000, with seven variations of trehalose and inulin weight ratio (table 2). 
Table 1: Formula of the insulin dry powder

\begin{tabular}{lll}
\hline Material & Function & Amount \\
\hline Insulin human & API & $1.735 \mathrm{mg}$ \\
HCl 0,1 M & Solubilizer & $0.5 \mathrm{ml}$ \\
Trehalose & Sugar Stabilizer & $(\mathrm{x}) \mathrm{mg}$ \\
Inulin & Sugar Stabilizer & $(1735-\mathrm{x}) \mathrm{mg}$ \\
HPMC E5 & Mucoadhesive & $2 \%(35.510 \mathrm{mg})$ \\
Poloxamer 188 & Enhancer & $0.5 \%(8.763 \mathrm{mg})$ \\
\hline
\end{tabular}

Table 2: Ratio of trehalose to inulin in the insulin dry powder formulation

\begin{tabular}{llll}
\hline Ratio trehalose: inulin & Formula & Trehalose (mg) & Inulin (mg) \\
\hline $1 / 0$ & F1 & 1735 & 0.00 \\
$5 / 1$ & F2 & 1446 & 289 \\
$2 / 1$ & F3 & 1156.7 & 578.3 \\
$1 / 1$ & F4 & 867.5 & 867.5 \\
$1 / 2$ & F5 & 578.3 & 1156.7 \\
$1 / 5$ & F6 & 289 & 1446 \\
$0 / 1$ & F7 & 0.00 & 1735 \\
\hline
\end{tabular}

\section{Preparation of dry powder formulation}

Insulin dry powder was formulated using the SFD method. Dry powder formulation consisted of solution preparation, which was ready for SFD, and proceeded with the SFD process. Preparation of the solution consisted of dissolving human recombinant insulin with $\mathrm{HCl}$ and other ingredients with water. Then, the solution was atomized through the nozzle, then sprayed on a vessel containing liquid nitrogen $\left(-196^{\circ} \mathrm{C}\right)$ to obtain a frozen droplet. Finally, the frozen droplet was put into a freeze dryer for primary and secondary drying to produce a dry powder.

\section{Optimization critical parameter of SFD process}

The SFD process consisted of a solution atomization process into liquid nitrogen and followed by a drying step with the FD process through solvent sublimation. Modifications to the equipment included the manufacture of a vessel for liquid nitrogen and a suitable nozzle and the use of a compressor to pump the solution through the nozzle to produce frozen droplets. The vessel should be made of metal which is about $30 \mathrm{~cm}$ high and the liquid nitrogen-filled at about 10 $\mathrm{cm}$ high, while the nozzle is placed about $10 \mathrm{~cm}$ above the liquid nitrogen surface.

The next step was the solution is fed into the nozzle and atomized into nitrogen vapor to produce frozen droplets [17]. In this method, freezing in the nozzle can be occured because it uses low temperatures [15]. To avoid freezing of the solution in the nozzle, the nozzle must be covered with a water coat previously filled with hot water. After freezing and most of the liquid nitrogen had evaporated, the frozen droplets were immediately removed and proceeded with the FD process. If the frozen droplets melted before the FD process, then they will melt and cannot produce dry powder. Other than that, if they were not immediately subjected to the FD process, the frozen droplets can be stored in a-80 ${ }^{\circ} \mathrm{C}$ freezer until the freeze drying process is carried out.

The solution resulting from the previous process was atomized through a nozzle, then sprayed on a vessel containing liquid nitrogen $\left(-196{ }^{\circ} \mathrm{C}\right)$ so that frozen droplets were obtained. The frozen droplets were then put into the Scanvac CoolSafe freeze dryers. After that, the primary drying was carried out at a temperature of $39^{\circ} \mathrm{C}$ at the beginning to-35 ${ }^{\circ} \mathrm{C}$ at the end of the primary drying. Primary drying was carried out below Tg for all formulations. After that, secondary drying was carried out for $4 \mathrm{~h}$ at $40^{\circ} \mathrm{C}$ to produce a small amount of residual water. In order to keep the results of freeze-dried powder stable and to avoid any damage or hygroscopicity, the freeze-dried powder is placed in a desiccator for further evaluation purposes. The organoleptic parameter and spherulite shape of dry powder had been the target before continuing to physicochemical characterization. These targets were decisive in analysing CPP on the SFD process.

\section{Physicochemical characterization of dry powder formulation}

The next step was the physicochemical characterization of dry powder consisted of identification of $\mathrm{Tg}$ and thermal energy with Mettler Toledo Differential Scanning Calorimetry (DSC) 1/500, analysis of crystallinity properties with X-Ray Powder Diffraction (XRPD), moisture content analysis with Ohaus Moisture Content Analyzer MB45, particle morphology analysis with Ametek Edax Scanning Electron Microscope (SEM) APOLLO X, particle size distribution analysis and EE. These results determined the quality of the product including high $\mathrm{Tg}$, amorphous crystallinity, low moisture content, spherulite shape, diameter range of 30-60 $\mu \mathrm{m}$ and high EE. Assay of insulin levels in the EE testing was carried out by High-Performance Liquid Chromatography (HPLC) method with reverse-phase HPLC method, which refers to the method of insulin assay in United States Pharmacopoeia (USP). A mixture of acetonitrile with $0.1 \%$ trifluoroacetic solution with a ratio of $30: 70$ was used as the mobile phase, with a flow rate of $1.0 \mathrm{ml} /$ minute and injection volume of $20 \mu \mathrm{l}$ [18].

\section{RESULTS}

In the early optimization, some atomized frozen droplets were melted, as a result, some of the powder coagulated and crystallized (fig. 1). The optimal formulation is achieved with a FD process of at least 50 hours without any delay. All seven formulas produced a white fine dry powder and proceeded with physicochemical characterization.

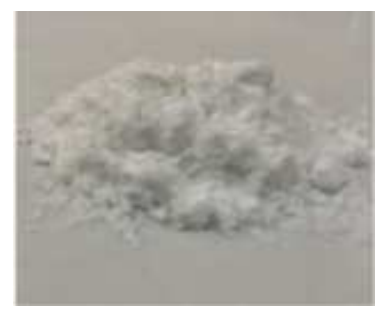

Fig. 1: Coagulated powder because of the slight lag time in the SFD process

All dry powder formulas (F1, F2, F3, F4, F5, F6, F7) produced endothermic peaks that absorbed heat with $\mathrm{Tg}$ values of $97.41{ }^{\circ} \mathrm{C}$, $105.97{ }^{\circ} \mathrm{C}, 108.09{ }^{\circ} \mathrm{C}, 111.66^{\circ} \mathrm{C}, 112.67{ }^{\circ} \mathrm{C}, 115.56^{\circ} \mathrm{C}$ and $117.98{ }^{\circ} \mathrm{C}$, respectively (fig. 2). In the dry powder F1, F2, F3, F4, F5, F6, F7 the required thermal energy values of-12.42,-167.62,-32.72,-180.70,$106.93,-50.07$, and-77.19 J/g, respectively.

Based on the results obtained, F1, F2, F3, F4, F5, F6, F7 dry powder were found to have moisture content percentages of $3.44 \%, 3.35 \%$, $3.02 \%, 2.64 \%, 2.41 \%, 2.20 \%$, and $2.19 \%$, respectively. These results showed a decrease of moisture with an increase of the inulin ratio.

The results observed on the XRPD diffractogram can be seen that F1 showed semicrystalline properties, whereas six other formulas showed amorphous properties (fig. 3).

Characterization of particle morphology using Scanning Electron Microscope (SEM) was carried out with observations at a magnification of 1000x (fig. 4). All seven dry powder formulas (fig. 4) were found to have spherulite shape and rough surface characteristics. 


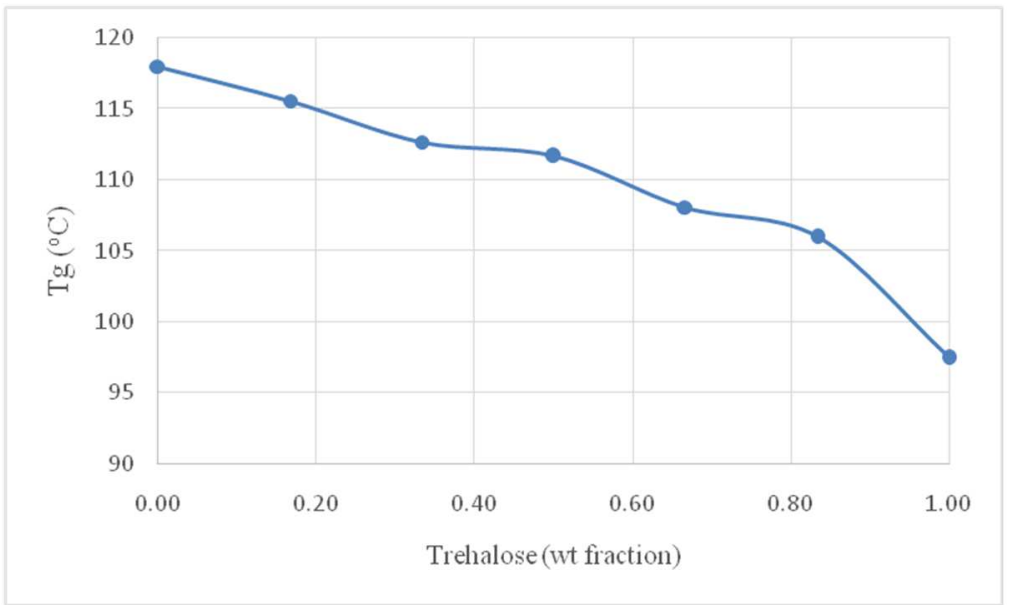

Fig. 2: Glass transition temperature (Tg) of maximally spray-freeze dried insulin dry powder based on wt fraction of trehalose
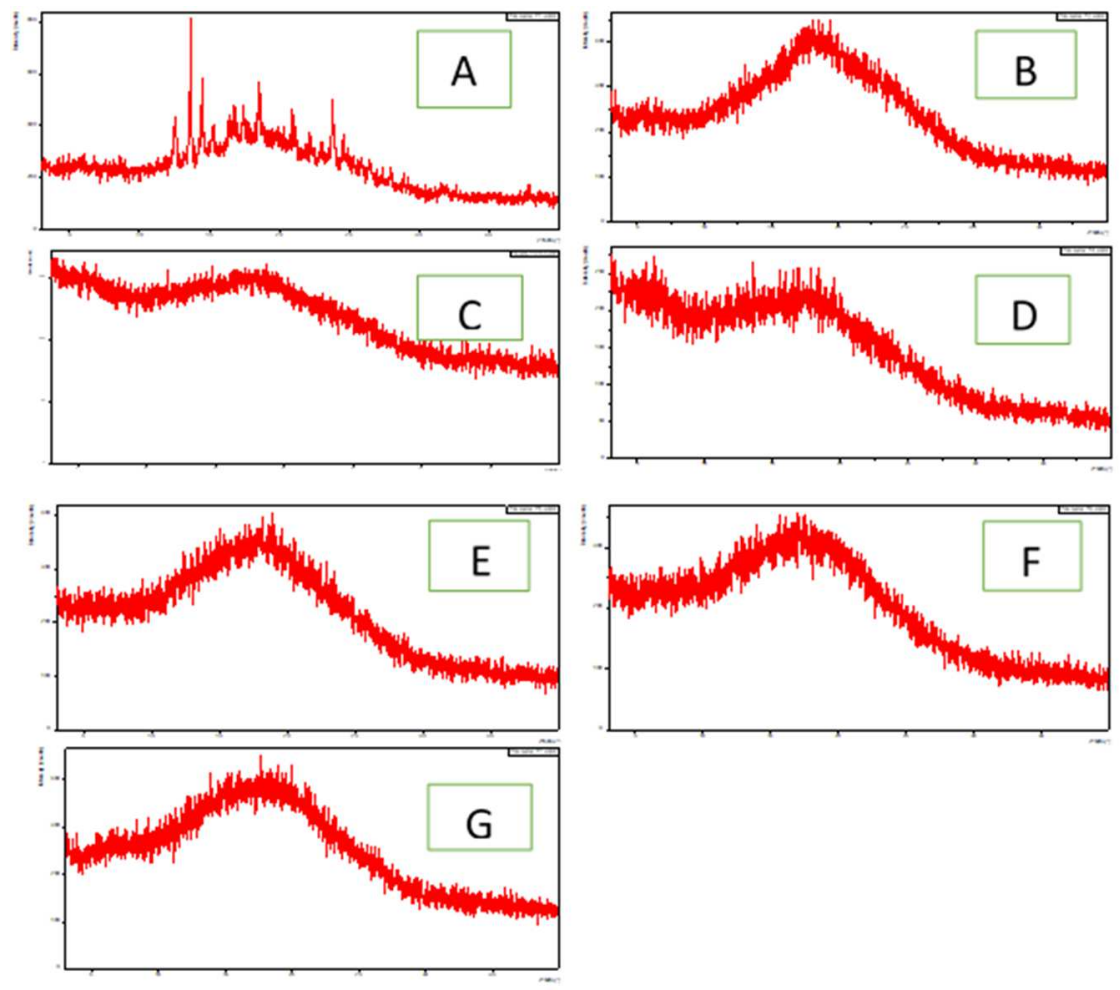

Fig. 3: XRPD diffractogram of (A) F1, (B) F2, (C) F3, (D) F4, (E) F5, (F) F6, (G) F7 dry powder formula

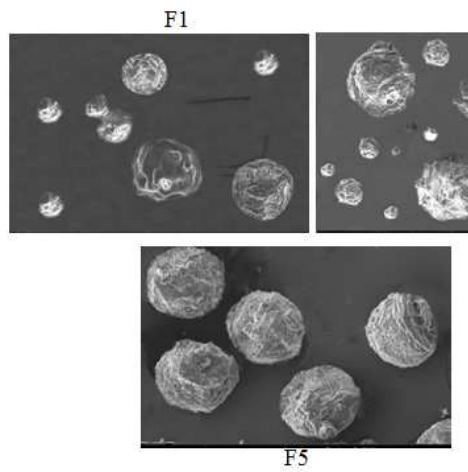

F2
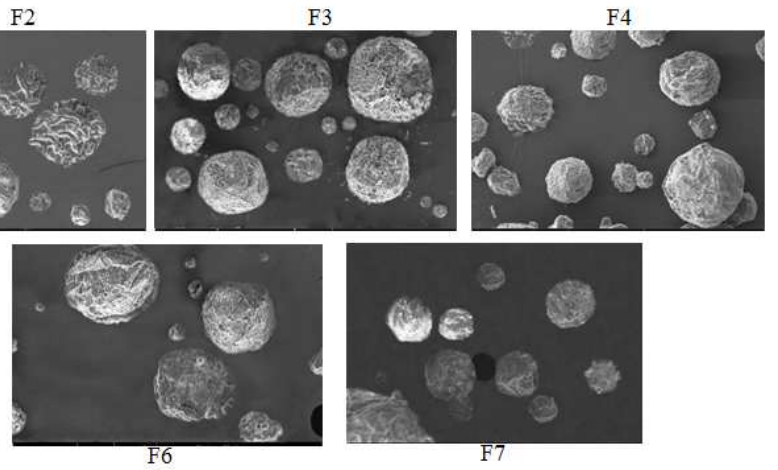

Fig. 4: Scanning electron micrographs of the insulin dry powders (A) F1, (B) F2, (C) F3, (D) F4, (E) F5, (F) F6, (G) F7, with a magnification of 1000x 
Particle size distribution of insulin dry powder in this study was observed using a binocular optical microscope with a magnification of $1000 x$. The calculation of statistical diameters from data obtained was divided into certain classes and the average diameter of the particles is calculated as shown in table

Table 3: Particle size of the insulin dry powder formulation

\begin{tabular}{lllllll}
\hline Formula & \multicolumn{2}{l}{ Average diameter statistic $(\boldsymbol{\mu m})$} & & \\
\cline { 2 - 5 } & $\mathbf{d}_{\mathbf{l n}}$ & $\mathbf{d}_{\mathbf{s n}}$ & $\mathbf{d}_{\mathbf{v n}}$ & $\mathbf{d}_{\mathbf{s l}}$ & $\mathbf{d}_{\mathbf{v s}}$ & \\
\hline F1 & 32.854 & 34.0597 & 35.2661 & 35.3096 & 37.8086 & \\
F2 & 30.7130 & 30.8985 & 31.0933 & 31.0863 & 31.4903 \\
F3 & 30.248 & 30.6938 & 31.0951 & 31.1461 & 31.9135 & 30.3708 \\
F4 & 31.972 & 32.7798 & 33.6817 & 33.608 & 35.5606 & 32.9301 \\
F5 & 31.4345 & 32.2813 & 33.064 & 33.1512 & 34.6869 & 37.7856 \\
F6 & 29.568 & 30.93 & 32.118 & 32.3535 & 34.632 & 36.1207 \\
F7 & 40.976 & 41.2665 & 41.5711 & 41.5590 & 42.1870 & 36.5305 \\
\hline
\end{tabular}

Insulin was analyzed using HPLC method with the addition of $2.0 \mathrm{ml}$ of $10 \mathrm{ppm}$ methyl parahydroxybenzoate (methyl paraben). The chromatogram of HPLC results produced two peaks, for insulin and methyl paraben, with retention time (RT) 2.64 and $5.02 \mathrm{~min}$, respectively. The resolution (Rs) is 7,287 and the coefficient of variance $(\mathrm{CV})$ of insulin area and nipagin area in system suitability testing (SST) were $1.205 \%$ and $0.631 \%$, respectively. The calibration curve obtained a correlation coefficient (r) of 0.999. Accuracy parameters at three different levels of concentration obtained \% recovery $99.62 \pm 0.67 \%, \quad 100.59 \pm 1.04 \%$, and $99.95 \pm 0.44 \%$, respectively. Precision parameter at three different levels [27], results showed a CV of $0.21 \%, 0.27 \%, 0.28 \%$, respectively.

Insulin concentration was calculated using the regression equation obtained. Regression plots were made between the area ratio of insulin to nipagin and the concentration of insulin (ppm) as presented in fig.5. Insulin concentration in the dry powder of F1, F2, F3, F4, F5, F6, F7 were found to be $94.29 \pm 0.29 \%, 101.28 \pm 0.75 \%, 99.997 \pm$ $0.39 \%, 99.78 \pm 0.35 \%, 98.32 \pm 0.34 \%, 98.30 \pm 0.68 \%, 92.38 \pm 0.17 \%$, respectively.

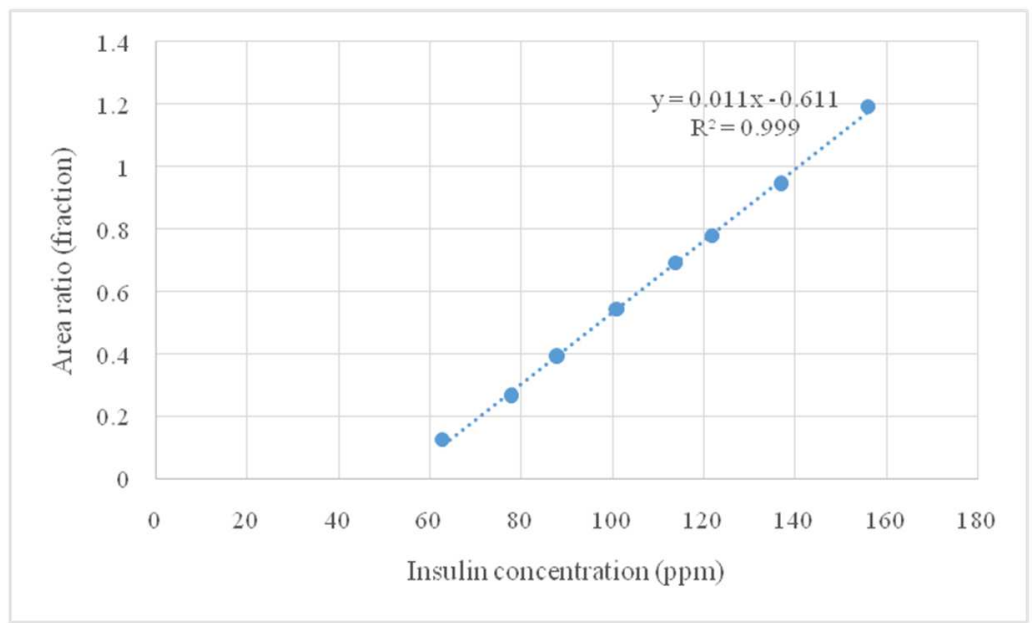

Fig. 5: Calibration curve of insulin with an addition of $10 \mathrm{ppm}$ methylparaben as an internal standard

\section{DISCUSSION}

Due to its stability problem, insulin is formulated in dry powder formulation using the Spray-Freeze Drying (SFD) method. This method is chosen because insulin is a thermal-sensitive product. In the early stage, optimization of the SFD method formulation was carried out because there were several critical process parameters, i. e interrupted process between atomization and FD as well as the interrupted process during FD. The critical response was organoleptic dry powder that showed coagulated and crystallized powder. Apart from that, the spherical shape of the morphology could not be attained. The organoleptic parameter and spherical shape of the dry powder had been the target before continuing the physicochemical characterization.

The optimization results showed a slight lag time between the atomization and the FD process, frozen droplets would be melting; as a result, some of the powder coagulated and crystallized (fig. 1). This problem was resolved by the immediate storage of frozen droplets in the freezer $\left(-80{ }^{\circ} \mathrm{C}\right)$ if the FD process is not carried out immediately. Another critical parameter is that the FD process should not be interrupted. Some formulations with interrupted processes obtained coagulated and crystallized powder. The optimal formulation is achieved with a FD process of at least 50 hours without any delay Other formulations with the interrupted processes during FD also obtained coagulated and crystallized powder because some frozen droplets had not dried completely so that they melted and affected other powders to become wet and coagulated.

After optimization, all seven formulas produced a white fine dry powder and proceeded with physicochemical characterization, including identification of glass transition temperature (Tg) and thermal energy, crystallinity properties, moisture content, particle morphology and particle size distribution. These characterizations were done in order to analyze CMA on trehalose and inulin ratio for seven variations of the formula.

Seven dry powder formulas produced endothermic peaks with increments of $\mathrm{Tg}$ value due to the increased inulin ratio. These results indicated an increase in the $\mathrm{Tg}$ value with an increase in the inulin ratio (fig. 2). Formulation using trehalose inulin combination sugar required greater energy than the trehalose formula in F1 dry powder. 
Five formulas with inulin showed high Tg due to the use of inulin in the formula. Highest Tg was shown by F7 because no trehalose was used in this formula. The high value of $\mathrm{Tg}$ indicated high physical stability of insulin dry powder formulation $[11,13]$.

All seven dry powder formulas were known to have moisture content percentages below $3.5 \%$. There was a difference in moisture content caused due to trehalose hygroscopic characteristic, which was susceptible to moisture. The use of inulin combinations reduced moisture content, it was seen that F4, F5, F6 and F7, which have a high inulin ratio showing the percentage of moisture content below $3 \%$ and it became lower with an increase in the inulin ratio. Four formulas i. e F4, F5, F6, F7 showed moisture content less than 3.0\%, indicating the reduction of moisture and high physical stability.

The results from XRPD diffractogram showed a peak difference of F1 compared to six other formulas. There were several peaks showing an increase in intensity that indicate crystal formation of F1 dry powder. Thus, in F1 there was an amorphous form along with crystals or what is called the semicrystalline form due to high humidity and trehalose hygroscopic characteristic. In general, freeze-dry amorphous powder preparations were hygroscopic, increasing the adsorption of water on the surface and disrupts the bond between the polymer and insulin through the hydrogen bonding mechanism, which induced the separation of the amorphous phase and the formation of crystals [19]. Six other formulas had amorphous properties due to the combination of inulin and trehalose. Amorphous crystallinity indicates high solubility and enhances the permeation for further study.

Particle morphology characterization using SEM showed that all seven dry powder formulas were found to have spherulite shape and rough surface characteristics, either for magnification of $250 \mathrm{x}$ and 1000x. The spherical shape occurs due to the SFD process, which involved atomization of the solution through a nozzle and optimization of CPP. The resulting rough surface characteristics were due to combined sugar trehalose and inulin, which were used to protect insulin and form a sugar glass system.

Particle size distribution analysis using a binocular optical microscope with a magnification of 100x obtained a histogram of the normal particle size distribution in seven dry powder insulin formulas. This was indicated by a histogram which is shaped like a bell and a relatively small standard deviation value in the range of 3.5751-6.3990. The smallest diameter was indicated by F3 dry powder, while the largest diameter was indicated by F1 dry powder. The relatively small standard deviation means that the variation in the particle size data is also relatively small, so it can be said that the dry powder has a homogeneous particle size distribution.

In this study, insulin dry powder was administered via the nose to brain delivery. Therefore, it is necessary to consider maximizing deposition in a very limited nasal area that only represents $5.2 \%$ of the total surface of the nasal cavity, namely the olfactory mucosa [20]. It is well known that the deposition of large particles or droplets (50$60 \mu \mathrm{m}$ ) occurs mainly at the nasal inlet, where this olfactory region is located [21-23]. However, if the diameter of the medium is too large, the formulation can be deposited in the initial part of the nose and can be quickly removed by sneezing or cleaning [24]. Thus, the specification of the dry powder formulation of insulin is expected to have a range between 10-60 $\mu \mathrm{m}$ so that particles can be deposited and can be delivered to the therapeutic target.

The diameters length-number ( $\mathrm{dln}$ ) mean were calculated from the measured statistical diameters. Based on the results of the observation on the insulin dry powder of the seven dry powder insulin formulas, the dln values for F1, F2, F3, F4, F5, F6 and F7 were $32.854 \mu \mathrm{m}, 30.713 \mu \mathrm{m}, 30.248 \mu \mathrm{m}, 31.972 \mu \mathrm{m}, 31.435 \mu \mathrm{m}, 29.568 \mu \mathrm{m}$, $40.976 \mu \mathrm{m}$, respectively. Based on the expected intranasal route particle size specification of 10-60 $\mu \mathrm{m}$, the particle size of the insulin dry powder met the required specification.

Efficiency encapsulation analysis of insulin in dry powder was analyzed using the HPLC method. In this study, methyl parahydroxybenzoate (methylparaben) was used as an internal standard. The HPLC method was chosen because it has a high level of selectivity and specificity compared to a spectrophotometer. The addition of methylparaben was carried out to reduce the error rate of analysis [18]. Column C18 (length $150 \mathrm{~mm} \times 4.6 \mathrm{~mm}$ ) was used as a column and a mixture of acetonitrile with $0.1 \%$ trifluoroacetic solution with a ratio of $30: 70$ was used as the mobile phase the mobile phase flow rate of $1.0 \mathrm{ml} /$ minute and the injection volume of $20 \mu \mathrm{l}$.

Screening for insulin wavelength in a phosphate buffer solution $\mathrm{pH} 6.8$ using a spectrophotometer was aimed for qualitative analysis and determination of the maximum wavelength of insulin for measurements using HPLC. Screening results showed that the maximum wavelength of insulin in the phosphate buffer $\mathrm{pH} 6.8$ is 276 $\mathrm{nm}$. An ultraviolet detector at a wavelength $276 \mathrm{~nm}$ was used as the detector in this assay. Prior to verification of the analytical method, a system suitability test was carried out earlier to ensure that the system used can produce observations that meet the requirements.

The HPLC chromatogram showed two peaks, including a peak of insulin and a peak of methylparaben. The insulin peak came out earlier at 2.64 min and methylparaben at 5.02 min with a tailing factor of 1.328 for insulin and 1.033 for methylparaben. The resolution (Rs) between the 2 peaks is 7,287, whereas the coefficient of variance (CV) of insulin area and methylparaben area in SST were $1.205 \%$ and $0.631 \%$, respectively. Thus, this method of analysis met the requirements, including the tailing factor $\leq 1.5$, Rs $\geq 2.0$ and $\mathrm{CV} \leq 2.0 \%[25,26]$.

The analysis method was verified, including linearity, accuracy, precision, and specificity parameters. The verification results show that the analysis method has met the requirements. The r-value of the calibration curve indicates a linear relationship between insulin concentration and area ratio of insulin to nipagin. Accuracy parameters at three different levels of concentration have met the criteria, with mean recovery value should be at least $100 \pm 2 \%$ at each concentration for three variations of concentration. According to ICH, precision should be performed at three different levels [27]; results showed that $\mathrm{CV}$ values have met the criteria of $\mathrm{CV} \leq 1 \%$. The determination of the specificity parameter also met the criteria indicated by the resolution value (Rs) $\geq 2$.

In this study, insulin concentration was calculated using the regression equation which was obtained by making insulin standard solutions at various concentrations. Insulin concentration analysis showed that F2, F3, F4, F5, and F6 which used a combination of trehalose and inulin obtained higher levels than F1 and F7 which only used inulin or trehalose. A combination of trehalose and inulin at a specific ratio can increase the protection of insulin during the formulation process and the environment. High EE on five formulas indicated the benefit of trehalose and inulin combination related to other physical characters, i.e., the high value of Tg and low moisture content. Highest Tg was shown by F7, while it showed the lowest value of EE, due to the absence of trehalose that caused the rigid structure of inulin in protecting insulin.

\section{CONCLUSION}

Based on the results, this study concluded that there were two critical process parameters in the SFD method. There should be no delay in the SFD process and when the FD is in operation, it should not be interrupted until the powder is dry. The optimal ratio for trehalose and inulin was shown by F4 with a ratio of 1:1.

\section{ACKNOWLEDGMENT}

The Author would like to thank Universitas Indonesia for funding this research through PUTI Grant with contract number NKB5/UN2.RST/HKP.05.00/2020. The authors would also like to thank to Dr. Wouter Hinrichs from Groningen Research Institute of Pharmacy, University of Groningen, Netherlands, for insightful suggestions and discussion about methodology.

\section{AUTHORS CONTRIBUTIONS}

All the authors contributed equally.

\section{CONFLICT OF INTERESTS}

Declared none 


\section{REFERENCES}

1. Saxenian H. Immunization financing: a resource guide for advocates, policy-makers, and program managers. Washington, DC: Resource Guide by Results for Development Institute; 2017.

2. Lai MC, Topp EM. Solid-state chemical stability of proteins and peptides. J Pharm Sci. 1999;88(5):489-500. doi: 10.1021/js980374e, PMID 10229638.

3. Wang W. Lyophilization and development of solid protein pharmaceuticals. Int J Pharm. 2000;203(1-2):1-60. doi: 10.1016/s0378-5173(00)00423-3, PMID 10967427.

4. Carpenter JF, Pikal MJ, Chang BS, Randolph TW. Rational design of stable lyophilized protein formulations: some practical advice. Pharm Res. 1997;14(8):969-75. doi: 10.1023/a:1012180707283, PMID 9279875.

5. Jiskoot W, Randolph TW, Volkin DB, Middaugh CR, Schöneich C, Winter G, Friess W, Crommelin DJ, Carpenter JF. Protein instability and immunogenicity: roadblocks to clinical application of injectable protein delivery systems for sustained release. J Pharm Sci. 2012;101(3):946-54. doi: 10.1002/jps.23018, PMID 22170395.

6. Hinrichs WLJ, Prinsen MG, Frijlink HW. Inulin glasses for the stabilization of therapeutic proteins. Int J Pharm. 2001;215(12):163-74. doi: 10.1016/s0378-5173(00)00677-3, PMID 11250102

7. Mensink MA, Van Bockstal PJ, Pieters S, De Meyer L, Frijlink HW, van der Voort Maarschalk K, Hinrichs WLJ, De Beer T. In-line near infrared spectroscopy during freeze-drying as a tool to measure efficiency of hydrogen bond formation between protein and sugar, predictive of protein storage stability. Int J Pharm. 2015;496(2):792-800. doi: 10.1016/j.ijpharm.2015.11.030, PMID 26608621

8. Tonnis WF, Mensink MA, de Jager A, van der Voort Maarschalk K, Frijlink HW, Hinrichs WLJ. Size and molecular flexibility of sugars determine the storage stability of freeze-dried proteins. Mol Pharm. 2015;12(3):684-94. doi: 10.1021/mp500423z, PMID 25581526.

9. Grasmeijer N, Stankovic M, de Waard H, Frijlink HW, Hinrichs WLJ. Unraveling protein stabilization mechanisms: vitrification and water replacement in a glass transition temperature controlled system. Biochim Biophys Acta. 2013;1834(4):763-9. doi: 10.1016/j.bbapap.2013.01.020. PMID 23360765.

10. Rodriguez Furlan LT, Lecot J, Perez Padilla A, Campderros ME, Zaritzky N. Effect of saccharides on glass transition temperatures of frozen and freeze dried bovine plasma protein. J Food Eng. 2011;106(1):74-9. doi: 10.1016/j.jfoodeng.2011.04.010.

11. Mensink MA, Frijlink HW, van der Voort Maarschalk KV, Hinrichs WLJ. How sugars protect proteins in the solid state and during drying. Eur J Pharm Biopharm. 2017;114:288-95. doi: 10.1016/j.ejpb.2017.01.024.

12. Allison SD, Chang B, Randolph TW, Carpenter JF. Hydrogen bonding between sugar and protein is responsible for inhibition of dehydration-induced protein unfolding. Arch Biochem Biophys. 1999;365(2):289-98. doi: 10.1006/abbi.1999.1175, PMID 10328824.

13. Teekamp N, Tian Y, Visser JC, Olinga P, Frijlink HW, Woerdenbag HJ, Hinrichs WLJ. Addition of pullulan to trehalose glasses improves the stability of $\beta$-galactosidase at high moisture conditions. Carbohydr Polym. 2017;176:374-80. doi: 10.1016/j.carbpol.2017.08.084, PMID 28927620.

14. Hinrichs WLJ. Specialty products I: biopharmaceuticals; 2017.
15. Ishwarya SP, Anandharamakrishnan C, Stapley AGF. Sprayfreeze-drying: A novel process for the drying of foods and bioproducts. Trends Food Sci Technol. 2015;41(2):161-81. doi: 10.1016/j.tifs.2014.10.008

16. Eggerstedt SN, Dietzel M, Sommerfeld M, Suverkrup $R$, Lamprecht A. Protein spheres prepared by drop jet freeze drying. Int J Pharm. 2012;438(1-2):160-6. doi: 10.1016/j.ijpharm.2012.08.035, PMID 22960322.

17. Pouya MA, Daneshmand B, Aghababaie S, Faghihi H, Vatanara A. Spray-freeze drying: a suitable method for aerosol delivery of antibodies in the presence of trehalose and cyclodextrins. AAPS PharmSciTech. 2018;19(5):2247-54. doi: 10.1208/s12249-0181023-2, PMID 29740758.

18. Surini S, Akiyama H, Morishita M, Nagai T, Takayama K. Release phenomena of insulin from an implantable device composed of a polyion complex of chitosan and sodium hyaluronate. J Control Release. 2003;90(3):291-301. doi: 10.1016/s01683659(03)00196-2, PMID 12880696.

19. Xie T, Taylor LS. Effect of temperature and moisture on the physical stability of binary and ternary amorphous solid dispersions of celecoxib. J Pharm Sci. 2017;106(1):100-10. doi: 10.1016/j.xphs.2016.06.017, PMID 27476771.

20. Xi J, Yuan JE, Alshaiba M, Cheng D, Firlit Z, Johnson A, Nolan A, Su WC. Design and testing of electric-guided delivery of charged particles to the olfactory region: experimental and numerical studies. Curr Drug Deliv. 2016;13(2):265-74. doi: 10.2174/1567201812666150909093050, PMID 26362143.

21. Cheng YS, Holmes TD, Gao J, Guilmette RA, Li S, Surakitbanharn Y, Rowlings C. Characterization of nasal spray pumps and deposition pattern in a replica of the human nasal airway. $\mathrm{J}$ Aerosol Med. 2001;14(2):267-80. doi: $10.1089 / 08942680152484199$, PMID 11681658.

22. Kundoor V, Dalby RN. Effect of formulation- and administrationrelated variables on deposition pattern of nasal spray pumps evaluated using a nasal cast. Pharm Res. 2011;28(8):1895-904. doi: 10.1007/s11095-011-0417-6, PMID 21499839.

23. Guo Y, Laube B, Dalby R. The effect of formulation variables and breathing patterns on the site of nasal deposition in an anatomically correct model. Pharm Res. 2005;22(11):1871-8. doi: 10.1007/s11095-005-7391-9, PMID 16091994.

24. Scherließ R, Trows S. Novel formulation concept for particulate uptake of vaccines via the nasal associated lymphoid tissue. Procedia in Vaccinology. 2011;4:113-9. doi: 10.1016/j.provac.2011.07.016

25. Shabir GA. Validation of high-performance liquid chromatography methods for pharmaceutical analysis. Understanding the differences and similarities between validation requirements of the US Food and Drug Administration, the US Pharmacopeia and the International Conference on Harmonization. J Chromatogr A. 2003;987(1-2):57-66. doi: 10.1016/s0021-9673(02)01536-4, PMID 12613797.

26. Kementrian Kesehatan Republik Indonesia. Farmakope Indonesia Edisi VI. Jakarta; 2020.

27. ICH guidelines. Q1A (R2) stability testing of new drug substances and products. 2nd revision, International Conference on Harmonization [internet]; 2003. Available from: http://www.fda.gov/download/regulatoryinformation/Guidan ces/ucm128204.pdf. 